Rabaska

Revue d'ethnologie de l'Amérique française

\title{
Folklore et ethnologie de l'Amérique française (Université de Sudbury)
}

\section{Marcel Bénéteau}

Volume 10, 2012

URI : https://id.erudit.org/iderudit/1013588ar

DOI : https://doi.org/10.7202/1013588ar

Aller au sommaire du numéro

Éditeur(s)

Société québécoise d'ethnologie

ISSN

1703-7433 (imprimé)

1916-7350 (numérique)

Découvrir la revue

Citer ce document

Bénéteau, M. (2012). Folklore et ethnologie de l'Amérique française (Université de Sudbury). Rabaska, 10, 337-339. https://doi.org/10.7202/1013588ar d'utilisation que vous pouvez consulter en ligne.

https://apropos.erudit.org/fr/usagers/politique-dutilisation/ 
franco-ontarien de folklore a pu améliorer ses connaissances en matière de diffusion par l'entremise de ce projet.

Une trousse PÉDAgogique - Dans le cadre de la tournée Ti-Jean et le nénuphar de la destinée, une trousse pédagogique accompagne la pièce et sera bientôt accessible au public intéressé. Elle a pour objectif d'encadrer les élèves de la quatrième à la sixième année du primaire, avant et après la pièce de théâtre, pour maximiser les retombées pédagogiques de l'expérience vécue au cours de la représentation. Cette trousse a été préparée avec l'appui d'une enseignante du conseil scolaire public, Jocelyne Gervais, d'une enseignante du conseil scolaire catholique, Julie PhilippeShillington, et de deux animateurs culturels, Danielle Blais et Joël Lauzon. Grâce à leur travail, la trousse propose des plans de leçon et des activités étroitement liées à la pièce ainsi qu'au programme scolaire, pour chaque année d'enseignement visée.

ROger Gervais

\section{Folklore et ethnologie de l'Amérique française}

Université de Sudbury

Sudbury (Ontario) P3E 2C6
Téléphone : (705) 673-5661

Télécopieur : (705) 673-4912

Courriel : mbeneteau@usudbury.ca

Toile : www.usudbury.com

\section{Enseignement}

Le département de Folklore et ethnologie de l'Amérique française offre toujours ses programmes de cours en direct et à distance. Les cours à distance demeurent une partie intégrale du programme et nous bénéficions comme avant des services de nos chargées de cours Diane Brazeau et Lucie Beaupré. Madame Beaupré continue également la révision de plusieurs de nos cours par correspondance. Luc Robert, artiste franco-ontarien et professeur au Collège Boréal de Sudbury, a fait une mise à jour au cours Expressions de l'art populaire, y ajoutant une perspective élargie sur le terrain franco-ontarien. Nous accueillons aussi Genia Boivin, doctorante au département de Folklore de l'Université de l'Alberta, à notre programme de cours à distance.

Encore cette année, nos cours en direct ont attiré un bon nombre d'étudiants d'autres disciplines. Nous avons offert des cours sur la médecine populaire, la chanson traditionnelle, les fêtes populaires et, pour la première fois, un cours sur les folklores du Canada, avec une attention particulière sur le folklore et le multiculturalisme : comment les diverses communautés du Canada utilisent des éléments de leur folklore pour maintenir leur identité et se présenter aux autres. Le Département continue à élargir ses partenariats avec d'autres départements de la fédération laurentienne. Nous travaillons aussi avec le département d'histoire pour créer des nouvelles mineures en Études franco-ontariennes et canadiennes-françaises. Enfin, nous avons présenté deux cours - un sur le conte populaire et l'autre sur les survivances médiévales 
dans la chanson traditionnelle - aux étudiants en littérature française de l'Université Laurentienne.

Comme à chaque année, le prix Germain-Lemieux a été décerné à l'étudiant dont le rendement scolaire a été jugé le plus méritant ; pour l'année scolaire 20102011, le prix a été remis à Caroline Vandergoten au cours de la soirée de la remise des diplômes en octobre 2011.

\section{Activités}

Une des activités capitales de l'année a sans doute été l'atelier sur la chanson traditionnelle présenté à l'Université de Sudbury le 2 mars par les Charbonniers de l'enfer lors de leur passage dans le nord ontarien. L'événement fut organisé par le département de Folklore, en partenariat avec le CFof et la Slague de Sudbury. Les étudiants en folklore et des élèves de plusieurs écoles secondaires de Sudbury ont eu droit à une heure de musique et de dialogue avec les membres du groupe qui ont apporté leurs perspectives en tant qu'artistes, chercheurs et passionnés de la chanson.

La fête annuelle de la Sainte-Catherine organisée par le département de Folklore et le Centre franco-ontarien de folklore a été un succès encore cette année, avec nos invités spéciaux de l'est ontarien, Les Bons Vivants. Les spectateurs ont également eu droit à un conte de Joël Lauzon du Centre franco-ontarien de folklore. Comme les années précédentes, l'auteur du présent rapport a aussi présenté quelques chansons de son répertoire du sud-ouest ontarien.

\section{Recherche et diffusion}

Le Département a été actif cette année sur le plan de la recherche et de la diffusion. Nous avons participé à deux journées internationales d'étude organisées par la COFRAM (Chaire de recherche du Canada en oralité des francophones minoritaires d'Amérique) et le CRBC (Centre de recherche bretonne et celtique) à Pointe-de-l'Église et à Brest en octobre et novembre 2011. Le sujet de ces rencontres était L'Apport des prêtres et religieux au patrimoine des minorités; nous avons présenté une analyse du travail des prêtres auteurs de chansonniers. Nous avons également présenté des communications à la rencontre annuelle de l'Association canadienne d'ethnologie et de folklore à Waterloo et au Congrès de l'Amérique française de la Fédération des sociétés d'histoire du Québec à Montréal.

Sur le plan local, nous continuons notre collaboration avec le CFOF pour le projet de l'IPFo (Inventaire du patrimoine franco-ontarien). Nous travaillons actuellement à la première phase de ce projet, qui comprend l'inventaire des fonds existants en patrimoine oral franco-ontarien. Une deuxième phase comprendra la cueillette de nouvelles données dans toutes les régions francophones de l'Ontario. Nous travaillons également avec le CFOF pour développer un partenariat avec la « Nation Métisse de l'Ontario ». Nous avons eu une réunion préliminaire à Sudbury (le 24 janvier) et une journée d'ateliers à Timmins (le 27 février) avec les membres de la NMo pour identifier des intérêts communs. Notre présentation lors des ateliers a été bien reçue et nous avons cerné deux possibilités de collaboration : 1) identification de sources métisses dans les fonds d'archives déjà constitués ; 2) inclusion de certaines communautés métisses dans la deuxième phase de cueillette de données par les équipes de l'IPFo. 
Nous continuons à développer les archives de folklore de l'Université de Sudbury, qui comprennent plus de 2000 enquêtes menées par nos étudiants depuis 1980. Avec l'aide de notre étudiante Caroline Vandergoten, nous avons entrepris un important projet de numérisation de notre collection sonore ; plus de 1000 cassettes ont été numérisées à ce jour. Nous développons en même temps une banque de données qui sera accessible aux étudiants et aux chercheurs de l'extérieur.

Enfin, le Département continue sa collaboration à deux projets de recherche importants : d'abord le GTRC dirigé par France Martineau de l'Université d'Ottawa, Le français à la mesure d'un continent: un patrimoine en partage (2011-2018), qui porte sur l'histoire des communautés francophones en Amérique du Nord. Ce projet est la suite du GTRC Modéliser le changement : les voies du français, que madame Martineau a dirigé de 2005 à 2010. Le Département maintient aussi sa participation comme partenaire ontarien de l'Encyclopédie du patrimoine culturel de l'Amérique française, sous la direction de Laurier Turgeon de l'Institut du patrimoine culturel de l'Université Laval. Nous avons dirigé la production d'un article pour l'Encyclopédie : « Le Centre franco-ontarien de folklore » (rédigé par Julie Philippe-Shillington) et nous préparons actuellement un article sur la chanson traditionnelle française en Ontario et un autre sur les Archives du département de Folklore et ethnologie de l’Université de Sudbury.

Marcel BéNÉteAu 